\title{
Representações de estudantes sobre heróis nacionais Histórias conectadas de Argentina, Brasil, Chile e Uruguai
}

\author{
Flávia Eloisa Caimi \\ Letícia Mistura
}

\section{SciELO Books / SciELO Livros / SciELO Libros}

CAIMI, F.E., and MISTURA, L. Representações de estudantes sobre heróis nacionais: Histórias conectadas de Argentina, Brasil, Chile e Uruguai. In: CERRI, L.F., ed. Os jovens e a História: Brasil e América do Sul [online]. Ponta Grossa: Editora UEPG, 2018, pp. 137-161. ISBN: 978-85-7798-248-6. https://doi.org/10.7476/9788577982486.0007.

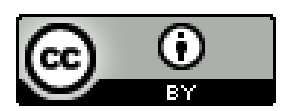

All the contents of this work, except where otherwise noted, is licensed under a Creative Commons Attribution 4.0 International license.

Todo o conteúdo deste trabalho, exceto quando houver ressalva, é publicado sob a licença $\underline{\text { Creative Commons }}$ Atribição 4.0. 


\section{REPRESENTAÇÕES DE ESTUDANTES SOBRE HERÓIS NACIONAIS: HISTÓRIAS CONECTADAS DE ARGENTINA, BRASIL, CHILE E URUGUAI}

Flávia Eloisa Caimi

Letícia Mistura

Na mitologia grega, heróis são tidos como semideuses, personagens situados em uma posição intermediária entre os homens e os deuses, cujos poderes eram superiores aos dos humanos em força e inteligência, embora não possuíssem a prerrogativa da imortalidade. A palavra provém do latim heros, e aos poucos foi sendo adotada para designar, nas sociedades ocidentais, o homem ilustre, famoso por suas façanhas e virtudes, que leva a cabo uma ação heroica em prol da coletividade.

A figura do herói, ao longo dos séculos, foi se plasmando nos textos de poetas, cronistas e historiadores, nos manuais escolares, em museus, monumentos, estatuária, toponímia, edificações, coleções arqueológicas e históricas, de acordo com as circunstâncias políticas e sociais de cada época e de cada sociedade. A história escolar se constituiu como o locus privilegiado para a disseminação de uma dada cultura histórica, fortemente vinculada às chamadas memórias de bronze, ao fortalecimento do sentimento patriótico e à construção da nação. No Brasil, a obra de José Veríssimo (1985), intitulada A Educação Nacional, é exemplar para se compreender o papel do ensino de História na construção da nacionalidade. Publicado no Pará em 1890 e reeditado no Rio de Janeiro em 1906, o livro reflete a visão de um autor preocupado com a educação e com os problemas pedagógicos da sua época. Como se vê, a obra é escrita um ano após a proclamação da República e reeditada no momento em que se discutia a chamada Nova República, momentos efervescentes da política nacional.

José Veríssimo era um homem do seu tempo, bastante interessado nas experiências educacionais de países como Estados Unidos, França, Alemanha, Inglaterra, Portugal, mas estava de costas para as nações latino-americanas. Ao tratar da história pátria e da educação nacional, o autor 
exalta as estratégias formativas adotadas pelas nações que considera mais adiantadas, nestes termos:

Nações há - e notarei que são as mais adiantadas e progressivas ciosíssimas do seu passado e tradições e de todos os monumentos que os relembram e perpetuam. Não só desveladamente os conservam e restauram, senão que carinhosamente vão erguendo novos ou rebuscando e esquadrinhando antigos, com que engrossam os seus tesouros de recordações pátrias, num tocante sentimento de amor dessas recordações. São agora inúmeros os museus e coleções que, templos do patriotismo, encerram as relíquias do passado nacional. Juntai a isso as inscrições lapidares consagrando o nascimento, a morte ou a simples passagem de um falecido compatriota ilustre, as estátuas, monumentos funerários e memórias diversas, com que esses povos diariamente consagram, para imortalidade e para a glória, aqueles que os ilustraram ou que os serviram algum feito que os afama e glorifica, e tereis uma constante, eloquente e sugestiva lição de história nacional (VERÍSSIMO, 1985, p. 102).

Nas sociedades contemporâneas, com interesses diversos e projetos distintos, elaboram-se diferentes (e coexistentes) versões do passado, protagonizadas por muitas vozes, representadas pela Igreja, pela Escola, pelo Exército, pela Imprensa, pelo Estado, pela língua nacional, pela história pátria, pelos rituais cívicos, dentre tantos outros agentes e linhas de força. Para este autor, também para muitos autores das gerações subsequentes, a escola tem um papel estratégico e decisivo na construção de um sentido comum do passado para o fortalecimento de uma dada identidade nacional, de modo a afiançar a soberania da nação. É um lugar privilegiado, na medida em que congrega gerações de crianças e jovens e, por meio de seus agentes, práticas, normas e rituais, apresenta-lhes certa seleção e combinação dessas diferentes vozes/ideias, que permite criar um sentido comum do que significa ser argentino, brasileiro, chileno ou uruguaio.

É forçoso reconhecer, no entanto, que a escola é uma instituição complexa, dificilmente redutível a um só formato ou a uma fórmula única. Os atores da instituição escolar são muitos, diversos, distintos, heterogêneos, e em suas práticas manifestam-se tanto divergências quanto convergências. Ademais, a esses atores incorporam-se mensagens provenientes de outras fontes, como as já mencionadas. Romero (2004) provoca-nos a pensar acerca dos efeitos da escolarização sobre as consciências dos estudantes, 
com essa instigante pergunta: o que fica no fundo da nossa consciência quando esquecemos os conteúdos específicos que a escola nos ensinou? Afirma o autor que as imagens que permanecem parecem naturais, mas não são naturais nem são neutras. Elas têm maior capacidade de operar quanto mais ocultas estejam, diante de qualquer exame crítico. Sem que nos demos conta, essas imagens guiam nossos juízos e nossas ações, constituem nosso sentido comum. Na mesma direção, Kusnick e Cerri (2014), alertam que o viés conteudista que tem predominado nas práticas de ensinar e aprender a história escolar não se mostra capaz de atingir os núcleos de sentido mais profundos nas concepções dos estudantes, nem tampouco de lhes oferecer subsídios para fazer uma leitura de mundo emancipatória.

Diante de tais pressupostos, o texto está consubstanciado no propósito de analisar os efeitos da cultura histórica sobre o pensamento de jovens na faixa etária de 15-16 anos que frequentam a escola secundária na Argentina, Brasil, Chile e Uruguai, notadamente no que diz respeito às suas representações sociais acerca dos heróis nacionais. Trata-se de buscar compreender as interpretações que os estudantes fazem do passado, considerando as representações sociais como lugar de confluência entre as práticas socioculturais, a memória coletiva e as suas identidades sociais.

O estudo aqui apresentado comporta a análise comparativa de quatro textos produzidos no âmbito do projeto internacional-interinstitucional Jovens e a História no Mercosul ${ }^{1}$, cada um deles representativo de um país envolvido na amostra - Argentina, Brasil, Chile, Uruguai -, excetuando-se apenas o Paraguai. Todos os textos estão circunscritos ao mesmo objeto, que é investigar o pensamento histórico dos jovens no que concerne às suas representações sociais sobre heróis nacionais, adotam o mesmo instrumento de produção e análise de dados, partilham de referenciais teóricos muito próximos, que serão detalhados adiante.

O tratamento do conjunto dos dados da pesquisa está amparado no conceito de histórias conectadas, segundo os estudos de Gruzinski (2003), Prado (2005), Vidal e Ascolani (2009), relacionando-se a uma definição inicialmente proposta pelo historiador indiano Sanjay Subrahmanyam, ao

\footnotetext{
${ }^{1}$ A descrição e a caracterização do Projeto constam da Apresentação deste livro.
} 
analisar a visão da historiografia europeia sobre o mundo asiático, mais especificamente a que trata do império português. A relevância de buscar as conexões das representações sociais de jovens secundaristas acerca dos heróis nacionais de Argentina, Brasil, Chile e Uruguai está direcionada às possibilidades de apreender a relação dialética entre os níveis global e local, as particularidades e o modo de articulação das tendências globais, distinguindo o que é próprio, específico, singular de um sistema e o que se manifesta como tendência mais geral, sem tratá-lo como objeto isolado, separado daquilo que lhe dá significado. Outro cuidado implicado na abordagem das histórias conectadas é o de evitar que se estabeleçam cisões polarizadas entre os objetos sob análise e, com isso, tratá-los a partir de relações de proeminência e subordinação (PRADO, 2005).

Serge Gruzinski (2003, p. 323) defende como uma das tarefas do historiador a de exumação das ligações históricas, uma vez que as histórias são múltiplas e não existe "uma História única e unificada, com ' $\mathrm{H}$ ' maiúsculo". Ainda, afirma o autor, deve-se considerar que essas histórias estão ligadas e comunicam-se entre si, razão pela qual "o historiador tem de se converter numa espécie de eletricista encarregado de restabelecer as conexões internacionais e intercontinentais que as historiografias nacionais e as histórias culturais desligaram ou esconderam, entaipando as suas respectivas fronteiras" (GRUZINSKI, 2003, p. 323).

Esta metáfora do eletricista é interessante, mas guarda o perigo de nos enredar em uma tendência de homogeneização das histórias dos países latino-americanos, pela semelhança de alguns de seus processos históricos como, por exemplo, "a colonização ibérica, a independência política, a formação dos Estados Nacionais, a preeminência inglesa e depois a norte-americana", dentre outros (PRADO, 2005, p. 12). De outra parte, é difícil sustentar a ideia de uma originalidade absoluta em cada uma dessas histórias nacionais, uma vez que atravessaram processos sincrônicos e características comuns.

Mediante tais ponderações, acreditamos que, em cada um desses quatro países, existem processos resultantes de trajetórias históricas particulares, mas que estão conectados por laços que articulam uma história 
comum, que pode ser pensada e estudada dentro de uma dinâmica que é, em grande medida, compartilhada. Este é um enfoque que permite reconhecer diferentes pontos de vista a partir de um mesmo mirante, e admite a coexistência de diferentes histórias em um mesmo contexto espacial e temporal. Assim, o olhar que estendemos para essas histórias conectadas está sustentado no esforço de ressaltar as simetrias e discrepâncias contextualizadas em suas particularidades e, ao mesmo tempo, em localizar pontos de contato, identificar sentidos de unidade, e construir perspectivas de continuidade entre os países que integram o estudo.

Como anteriormente anunciado, focalizaremos a análise sobre quatro estudos que debruçam sua atenção em uma questão específica do questionário padronizado, a de número 33, que solicita aos estudantes escreverem o nome de três heróis que considerem importantes para o seu país, em ordem descrescente e hierárquica. Estas respostas foram registradas em letra de forma (tipo bastão), o que favoreceu a leitura dos arquivos escaneados do questionário por um software de reconhecimento de caracteres e marcas, gerando uma linha de planilha para cada questionário respondido.

Três dos quatro estudos em análise - Argentina, Brasil e Chile serviram-se do software Evoc 2000, utilizado no processamento dos dados gerados pelas colunas referentes à hierarquização de heróis/respostas (herói 1, herói 2, herói 3). O software foi criado por Pierre Vergès, com base do conceito de núcleo central, vinculado à Teoria das Representações Sociais, que orientou os mesmos estudos acerca da estratégia de produção e análise dos dados empíricos, como veremos a seguir. O software Evoc opera com a construção de duas variáveis: frequência da menção de determinado nome e sua ordem média de evocação, ou seja, a posição média em que ele aparece quando os nomes são citados. Por exemplo, um nome que aparecesse em primeiro lugar em todas as evocações teria uma ordem média de evocação igual a um $(\mathrm{OME}=1)$, e outro que sempre aparecesse em terceiro lugar, teria OME igual a três. Assim, quanto menor a OME, mais prontamente e mais prioritariamente o nome foi lembrado/evocado. Nomes que apresentam uma grande frequência e uma baixa OME são aqueles que muito provavelmente pertencem ao núcleo central da representação social. Nomes com alta 
frequência, mas alta OME, assim como nomes com baixa frequência, mas baixa OME, figuram nas zonas intermediárias, enquanto nomes com baixa frequência e alta OME são localizados no núcleo periférico. O tratamento dos dados empíricos do Uruguai consubstanciou-se pela análise da frequência e porcentagem das menções, cotejando os dados hierarquicamente, elaborando um ranking de heróis escolarizados e individualmente (por herói/ estudante), buscando padrões ou regularidades de respostas.

Os estudos mobilizaram um montante de 3312 respondentes que preencheram pelo menos uma das lacunas de forma legível, totalizando 8404 evocações/menções - de 9936 possíveis, o que significa que 1532 lacunas permaneceram em branco, caracterizando-se como fator importante de análise em todos os estudos. Ao mesmo tempo, mais de 8 mil evocações de heróis foram registradas por jovens de 15 a 16 anos. Embora a amostra que aqui expomos e analisamos guarde grandes disparidades, como o número assimétrico de respondentes entre os países ${ }^{2}$ e a sua dispersão geográfica interna a cada nação, acreditamos na exemplaridade das interpretações possíveis pelo material empírico, na medida em que permitem uma aproximação do mundo de significados construído pelos estudantes a respeito de uma representação específica, o herói nacional, que se consistiu em categoria de análise dos estudos dos quatro países.

\section{SOBRE A CATEGORIA CENTRAL DE ANÁLISE: REPRESENTAÇÕES SOCIAIS DE HERÓIS NACIONAIS}

O que significa pensar em herói como uma categoria de análise? Sobretudo, implica tomá-lo como ente de significados e compreender o seu próprio processo histórico de constituição, como tal, no imaginário ocidental. Anne-Marie Thiesse (2001/2002), ao descrever o processo de construção das identidades nacionais dos Estados-Nação europeus no século XIX, cria uma espécie de check-list identitária, cuja matriz de constituição da nacionalidade envolve a inventariação de um passado comum, elevado

\footnotetext{
${ }^{2}$ Contabilizamos 965 respondentes na amostra da Argentina; 1937 respondentes na amostra do Brasil; 182 respondentes na amostra do Chile; e 228 respondentes na amostra do Uruguai. Estes números referem-se aos participantes que escreveram pelo menos um nome entre os três espaços reservados.
} 
a patrimônio coletivo, e destaca o enorme esforço pedagógico requerido na elaboração de novas identidades coletivas, como no caso da formação dos Estados Nacionais analisados em seus estudos. A autora traz uma perspectiva interessante, já que aborda o momento de gestação da própria ideia de nação, um contexto de mudança radical, muito mais do que de cartografia ou limites políticos, de representações.

De acordo com Thiesse (2001/2002, p. 8), uma nação que se pretenda "comunidade de nascimento", inscrevendo "igualdade e fraternidade de princípio entre seus membros", deve se estabelecer em termos de ancestrais fundadores, com uma narrativa histórica que perpetue a ideia de continuidade, a despeito dos conflitos que a precederam. Isto inclui uma galeria de heróis, uma língua nacional e elementos simbólico-imagéticos, materiais ou imateriais em que a nação esteja inscrita, como monumentos, artes plásticas em geral, folclore, etc. Acompanhando os processos de construção dos Estados-Nação europeus, como a Inglaterra, a França e a Alemanha, é possível visualizar com clareza esta lista operando como uma matriz de construção representacional do nacionalismo. Thiesse (2001/2002) visualiza, nessa padronização, mais do que uma limitação entre o que é o específico no universal (a função principal do construto da identidade nacional), a exposição do êxito e do potencial de generalização legado por esta revolução de representações, que supera as esferas monárquicas e militares. Elas "não são percebidas como o produto de uma reconfiguração homogeneizante das diferenças, mas como formações sui generis perfeitamente autônomas" (THIESSE, 2001/2002, p. 13), afirmando-se em uma atemporalidade forjada, pressuposta.

José Murilo de Carvalho (1998) recupera um movimento muito semelhante, ao construir um quadro da elaboração do imaginário popular no processo de legimitação do sistema republicano brasileiro, gestado em uma conjuntura de disputas ideológicas e políticas, e mais ainda, de simbologias e alegorias. Ao menos três grandes correntes ideológico-discursivas, o liberalismo à americana, o jacobinismo à francesa e o positivismo procuraram projetar, em diversas tentativas e incursões, os delineios de uma imagem do novo regime, "cuja finalidade era atingir o imaginário popular e recriá-lo dentro dos valores republicanos" (CARVALHO, 1998, p. 
9-10). Segundo este autor, para além da legitimação política, novos regimes necessitam de adesão afetiva, pois era preciso operacionalizar símbolos universais, facilmente reconhecíveis, em que os discursos encontrassem morada. Nesses símbolos, forjados como poderosos instrumentos de adesão, estariam inscritos os elementos que compunham a nação e, especialmente, os que encontrassem uma correspondência na comunidade de sentido (ou imaginação) preexistente no imaginário popular. Se esta correspondência inexistisse, a relação de significado não se estabeleceria, e o símbolo cairia no esquecimento.

Neste processo, a criação de um herói-símbolo é, segundo Carvalho (1998, p. 55), um instrumento eficaz de legitimação, já que pode ser facilmente relacionado e impresso no imaginário popular: heróis são “[...] encarnações de ideias e aspirações, pontos de referência, fulcros de identificação coletiva”. É onde se aporta o processo de heroificação, segundo o autor, na transmutação da figura real, humana, a fim de torná-la um arquétipo a serviço de uma coletividade de valores. A construção de um herói requer grande e trabalhoso investimento, já que é preciso, ao mesmo tempo, produzir uma figura que contenha em si uma potência de mobilização afetiva e de ideais coletivos, também que corresponda a um modelo ético, moral e ideológico idealizado tanto pelo regime político quanto pela população. O apelo do herói, de acordo com o autor, precisa ser o de totem cívico, operando pela unidade de diferentes, pelo universalismo. Assim foi o herói consagrado pela República brasileira, Tiradentes, cujo apelo acabou por unir em representação as três vertentes republicanas que disputavam por supremacia discursiva. O herói acabou por tornar-se símbolo nacional, não apenas republicano.

No início deste texto mencionamos a criação de heróis pelas sociedades ocidentais. Até então, enfatizamos seu importante papel na construção da nacionalidade e na legimitação de regimes políticos. No entanto, e como nos lembra Anne-Marie Thiesse (2001/2002), é impensável separamos desses processos o esforço depreendido pela esfera pedagógico-escolar, na tarefa de constantemente elaborar, transmitir e legitimar as narrativas do passado vinculadas à memória pátria e à história oficial da nação. De 
forma especial e com espaço curricular privilegiado, a disciplina de História tem sido a principal disseminadora desse empreendimento pedagógico, tal como anunciava José Veríssimo (1985). À história escolar delegou-se, por muito tempo, estritamente esta função, aportada pelo próprio conhecimento disciplinar.

Como sabemos, a grande crise epistemológica enfrentada pela História como disciplina, a partir principalmente de meados do século XX, veio a questionar, também, a história escolar, como anunciado por Mario Carretero (2010), colocando em xeque o perigoso narcisismo dos relatos históricos da nação (a nossa nação). Eles carregam consigo fragilidades no que tange à construção da alteridade e o respeito ao outro, o não-nosso, o diferente. Nesse caso, as histórias que compunham o modelo histórico-pedagógico, as grandes epopeias da pátria, mais desagregam do que unificam grupos, sejam sociais, culturais ou religiosos, e populações. A história escolar entra em disputa com outras representações, provenientes de narrativas e relatos advindos das produções culturais e midiáticas, da história da família, das práticas cotidianas, dos diferentes pertencimentos religiosos, etc. Quando não possui arsenal inclusivo destas representações (e muitas vezes colocando-se em conflito com elas) em sua matriz disciplinar, a história escolar fragiliza-se diante dos jovens estudantes, permanecendo incapaz de lhes ajudar na construção de suas identidades, de seu futuro. Ao disseminar um relato canônico inquestionável, a história escolar oportuniza a construção de apenas uma memória histórica ou coletiva, de uma versão da história, viabilizando a formação de representações sociais igualmente limitadoras.

Junto da proposta de visualização de heróis como evocações das representações possibilitadas pelo saber histórico escolar, os quatro estudos que ora analisamos procuram compreender as menções do grupo de estudantes, participantes do projeto, tanto em relação às suas interpretações pessoais da realidade, como indivíduos produtores de conhecimento, quanto em relação à sua participação em uma comunidade cultural, que implica na inserção em uma cultura histórica e na formação da consciência histórica. Esta premissa ajuda-nos a traçar os alicerces teórico-conceituais dos estudos, que compartilham algumas semelhanças: os quatro mobilizam 
sua análise por meio dos conceitos de cultura histórica, consciência história e representações sociais (ou imaginários coletivos).

\section{CULTURA HISTÓRICA, CONSCIÊNCIA HISTÓRICA E REPRESENTAÇÕES SOCIAIS}

Nos estudos aqui analisados, entende-se cultura histórica como o conjunto organizado de referenciais imagéticos, ideias, valores, conhecimentos e atitudes, que são a expressão visível e viva da consciência histórica (RÜSEN, 1994, 2001, 2007, 2009). A cultura histórica é exercida na e pela consciência histórica, fornecendo orientação temporal aos indivíduos para a vida prática e para a compreensão de si mesmos. Segundo Rüsen (2009), a cultura histórica, como todas as demais culturas, é multidimensional e contém expressões morais, pedagógicas, políticas e retóricas. Este autor distingue três dimensões básicas da cultura histórica, que são responsáveis por distintos critérios de sentido: 1) uma dimensão política, que diz respeito à legitimação de certa ordem política e a relações de poder; 2) uma dimensão estética, "relacionada com a eficácia psicológica das interpretações históricas, ou com a parte de seus conteúdos que afetam os sentidos humanos" (RÜSEN, 2009, p. 172); e 3) uma dimensão cognitiva, que se expressa nos eventos passados significativos para o presente e seu futuro, na qual concorre fundamentalmente o aspecto do conhecimento. Pode-se concluir, então, que a cultura histórica refere-se ao conjunto de operações da memória histórica e da consciência histórica, que se efetivam em determinado contexto social. Neste sentido, é na cultura histórica que se encontra a articulação prática e operante da consciência histórica em determinada sociedade.

Por sua vez, a consciência histórica pode ser definida como um aspecto inerente da vida mental, pelo qual se procede ao exercício indispensável de atribuir significado ao tempo; ou seja, reconhecer e significar o passado, de modo a orientar as ações presentes, tendo em vista as expectativas do futuro que se almeja. Trata-se de um processo mental de criação de sentido, sem o qual a vida prática se tornaria impossível, uma vez que é pela consciência histórica que o sujeito, seja no plano individual ou coletivo, estabelece determinada relação com o passado e produz uma explicação 
de si mesmo e do mundo, da existência humana e da cultura. Esta produção mental de sentido compreende um todo formado por pontos de vista, representações, compensações e projeções, que estão na base das tomadas de decisão e de ação sobre o mundo.

A consciência histórica, de acordo com Rüsen (2001), é produzida por meio de uma operação de narrativa histórica (de vida, individual, coletiva, social), da qual nenhum ser humano prescinde, já que vive em constante interpretação da realidade. Por meio desta operação de narrar, o ser humano formula e reformula representações e condições de continuidade da vida, nela instituindo identidade por meio da memória. Neste caso, a narrativa que se produz sobre a experiência do homem no tempo, entendida como história, é produtora e produto, simultaneamente, da consciência histórica. Segundo Rüsen (2001), a consciência histórica abrange quatro diferentes tipos de constituição de sentido, presentes tanto nas narrativas historiográficas, e em suas formas de comunicação, sendo a história escolar uma delas; quanto na elaboração de sentido à vida prática, cotidiana, comum a todos. Estes tipos de constituição de sentido acontecem por meio de operações de significação, envolvendo a memória da compreensão/afirmação das formas de viver e ordenamentos do mundo real e de suas origens (constituição tradicional de sentido); de regularidades/regras gerais do agir (constituição exemplar de sentido); de acontecimentos que questionem ou estabeleçam contraponto à ordem histórica vigente (constituição crítica de sentido); e de transformações a partir do confronto com formas de viver estranhas ou alheias às próprias (constituição genética de sentido). É importante destacar que esta tipologia não impõe ordem, linearidade ou sequencialidade: todas estão presentes no plano de constituição de sentido mental, em menor ou maior grau. Cada tipo é acompanhado por um sentido de tempo, por uma concepção de continuidade, e implica um modo de comunicação e de identidade.

A Teoria das Representações Sociais (TRS), elaborada no final dos anos 1950 e início da década de 1960 por Serge Moscovici (1978), apresenta a preocupação em construir uma psicologia social que apreenda os fenômenos sociais (crenças e ações) em sua gênese construtiva, como resultado de processos psicológicos e sociológicos. Tem como objetivo 
central compreender "como se formam e como funcionam os sistemas de referência que utilizamos para classificar pessoas e grupos e para interpretar os acontecimentos da realidade cotidiana" (ALVES-MAZZOTTI, 1994, p. 60). As representações sociais consistiriam, portanto, em um complexo de significados produzidos coletivamente para dar sentido às experiências cotidianas, originando-se nas interações sociais de que fazem parte os membros de determinado grupo. Tais representações são apropriadas pelos sujeitos em um processo ontogenético, mas se ativam sob a forma de identidades sociais e incidem como base, tanto comportamental quanto de tomadas de decisão e de posição dos indivíduos.

Visualizando o edifício teórico construído pelos quatro estudos aqui analisados, justificamos e compreendemos seu interesse em focalizar, dentro de um vasto número de importantes questões no questionário aplicado, o material obtido pela questão que solicitava a evocação de heróis pelos jovens estudantes. Tomar o herói como categoria de análise permite enxergar o movimento dinâmico entre as representações sociais, a memória histórica e coletiva, o conhecimento histórico escolar e a cultura histórica, uma vez que resguarda, em um único nome/representação, vestígios de uma realidade cultural, de construção de significados e indícios da força da cultura histórica em ação nos contextos de escolarização.

Ao final dos anos de 1980, Paulo Miceli conduziu um estudo sobre ensino de história e heróis, por meio de uma amostra de dados produzidos a partir de questionários (questões de livre resposta) com 267 estudantes brasileiros dos quatro anos finais do Ensino Fundamental e dos três anos do Ensino Médio, à época denominados primeiro e segundo graus. Caracterizando a escola como um viveiro de heróis, Miceli (1997) destaca o papel instrumental da escolarização dos heróis nas disputas históricas pelas versões do passado e no reforço de uma memória histórica específica. No estudo de Miceli (1997), os heróis que sobressaíram primariamente entre os estudantes foram Dom Pedro I, como prócer da pátria e pai fundador; e Tancredo Neves, político brasileiro, o primeiro presidente eleito pós-Regime Militar, cuja morte prematura contribuiu em sua inscrição, nas representações coletivas, como mártir, símbolo de uma esperança frustada para o progresso do país. O estudo do autor ajuda a compreender 
como uma amostra em análise, mesmo pequena, que envolva o ensino de História e a produção de heróis pela memória histórica, nos aproxima do que Michel De Certeau (1988) entende como a tarefa da operação de análise história: historicizar o atual, conferindo-lhe um lugar próprio e exemplar e, ao recortar dados intencionalmente, abrir uma fenda na coerência entre passado, presente e futuro, evidenciando o que falta a um projeto de futuro. Aqui, abordamos estudos que, ao recortarem uma fatia da realidade da história escolar em relação com a cultura histórica, e seu poder em formular representações coletivas, permite-nos abrir uma fenda para compreendermos o que faz falta nesse cenário.

\section{CONECTANDO AS REPRESENTAÇÕES SOCIAIS SOBRE HERÓIS NACIONAIS ENTRE JOVENS ARGENTINOS, BRASILEIROS, CHILENOS E URUGUAIOS}

Mediante os pressupostos conceituais e metodológicos já anunciados, mobilizamos os esforços no sentido de analisar os resultados da pesquisa realizada nos quatro países, com base nos textos produzidos pelos pesquisadores da Argentina (AGUIRRE; RUIZ, 2017), Brasil (CERRI; CAIMI; MISTURA, 2017), Chile (GONZÁLEZ CALDERÓN; CERRI; ROSSO, 2016) e Uruguai (ALVEZ CAVANNA; QUIRICI, 2017). Considerando que os quatro estudos derivam de uma pesquisa interinstitucional/internacional, cujos aportes teórico-metodológicos são muito semelhantes, observaram-se diversos pontos de conexão entre os seus resultados, ainda que não estejam ausentes as diferenças e as singularidades de cada país.

Dentre os quatro estudos, três deles, Argentina, Brasil e Chile, adotam como instrumental metodológico o Software EVOC 2000, que permite localizar o provável núcleo central e, também, o sistema periférico da representação social. O estudo de Alvez Cavanna e Quirici (2017), ainda que não tenha feito uso desse instrumento, também oferece elementos para situar o núcleo central e o sistema periférico das representações sociais dos jovens estudantes acerca dos heróis nacionais. Para um cotejo dos resultados, apresentamos a Tabela 1 com os dados que compõem o núcleo central das representações dos estudantes de cada um dos quatro países. 
Tabela 1 - Heróis Nacionais presentes no núcleo central das representações sociais

\begin{tabular}{|c|c|c|c|c|c|}
\hline & & $\mathbf{A R}$ & GENTINA & & \\
\hline Frequência $\geq 259$ & 9 e $\mathrm{OME} \leq 2$ & & Frequência $\geq 259$ e $\mathrm{OME} \geq 2$ & & \\
\hline San Martín & 626 & 1,42 & En Blanco & 547 & 2,16 \\
\hline Belgrano & 514 & 1,90 & Sarmiento & 264 & 2,473 \\
\hline Frequência $<259$ & 9 e $\mathrm{OME}<2$ & & Frequência < 259 e OME > 2 & & \\
\hline Cristobal Colón & 23 & 1,73 & Perón & 136 & 2,022 \\
\hline Nadie & 11 & 1,54 & Eva Perón & 101 & 2,08 \\
\hline & & & Maradona & 56 & 2,17 \\
\hline & & & Favaloro & 44 & 2,27 \\
\hline & & & Kirchner & 32 & 2,50 \\
\hline & & & Moreno & 24 & 2,33 \\
\hline & & & Rosas & 22 & 2,59 \\
\hline & & & Messi & 18 & 2,16 \\
\hline & & & Mitre & 17 & 2,70 \\
\hline & & & Roca & 12 & 2,00 \\
\hline & & & RASIL & & \\
\hline Frequência $>=13$ & 34 e $\mathrm{OME}<1,9$ & & Frequência $>=134$ e OME $>=1,9$ & & \\
\hline & & & Lula & 610 & 1,957 \\
\hline $\begin{array}{l}11 \text { iradentes } \\
\text { Vargas }\end{array}$ & $\begin{array}{l}4 / 1 \\
440\end{array}$ & $\begin{array}{l}1,841 \\
1,884\end{array}$ & Nomes do esporte & 389 & 2,100 \\
\hline $\begin{array}{l}\text { vargas } \\
\text { J. Kubitschek }\end{array}$ & $\begin{array}{l}440 \\
413\end{array}$ & $\begin{array}{l}1,884 \\
1,814\end{array}$ & Ressignificação & 303 & 1,993 \\
\hline Cabral & 396 & $\begin{array}{l}1,014 \\
* 1,528\end{array}$ & Irreverência & 216 & 1,977 \\
\hline D. Pedro I & 269 & 1,695 & Princesa Isabel & 186 & 2,016 \\
\hline Religiosos & 165 & 1,784 & Nomes da música & 145 & 2,269 \\
\hline & & & Dilma & 137 & 2,328 \\
\hline Frequência $<134$ & e $\mathrm{OME}<1,9$ & & Frequência $<134$ e OME $>=1,9$ & & \\
\hline D. Pedro II & 120 & 1,883 & Colombo & 197 & 1,938 \\
\hline Carlos Chagas & 19 & 1,684 & Santos Dumont & 126 & 1,921 \\
\hline Chico Mendes & 19 & 1,789 & Zumbi & 94 & 1,979 \\
\hline Zilda Arns & 12 & *1,667 & $\mathrm{FHC}$ & 56 & 2,071 \\
\hline Ant. Conselheiro & 12 & 1,833 & Deodoro da Fonseca & 38 & 2,158 \\
\hline Caxias & 12 & 1,833 & Collor & 25 & 2,120 \\
\hline & & & Machado de Assis & 25 & 2,200 \\
\hline & & & Niemeyer & 25 & 2,240 \\
\hline & & & Joaquim Barbosa & 18 & 2,056 \\
\hline & & & Bento Gonçalves & 16 & 2,125 \\
\hline & & & Rondon & 14 & 2,143 \\
\hline & & & Prestes & 13 & 2,077 \\
\hline & & & Drummond & 11 & 2,091 \\
\hline & & & Hitler & 11 & 2,182 \\
\hline & & & Maria da Penha & 10 & 2,300 \\
\hline & & & Barão de Mauá & 10 & 2,400 \\
\hline & & & Jose de Alencar & 10 & 2,400 \\
\hline
\end{tabular}


conclusão

\begin{tabular}{|c|c|c|c|c|c|}
\hline \multicolumn{6}{|c|}{ CHILE } \\
\hline \multicolumn{3}{|l|}{ Frequência $\geq 36$ e $\mathrm{OME} \leq 1,9$} & \multicolumn{3}{|l|}{ Frequência $\geq 36$ e $\mathrm{OME} \geq 1,9$} \\
\hline Bernardo o'Higgins & 91 & 1,87 & & & \\
\hline Arturo Prat & 72 & 1,87 & Manuel Rodríguez & 54 & 1,96 \\
\hline José Miguel Carrera & 55 & 1,70 & & & \\
\hline \multirow[t]{2}{*}{ Frequência < 36 e OME < 1,9 } & & & \multicolumn{3}{|l|}{ Frequência < 36 e OME > 1,9 } \\
\hline & & & Irreverencia & 22 & 2,14 \\
\hline Salvador Allende & 20 & 1,85 & Cambio significado & 13 & 2,15 \\
\hline Pedro de Valdivia & 13 & 1,53 & Lautaro & 9 & 2,33 \\
\hline \multirow[t]{2}{*}{ Cristóbal Colón } & 10 & 1,60 & Diego de Almagro & 7 & 2,00 \\
\hline & & & Violeta Parra & 7 & 2,42 \\
\hline \multicolumn{6}{|c|}{ URUGUAI } \\
\hline \multirow[t]{2}{*}{ Frequência $>=39$ e $\mathrm{OME}<1,9$} & & & \multicolumn{3}{|l|}{ Frequência $>=39$ e OME $>=1,9$} \\
\hline & & & En Blanco & 160 & 2,263 \\
\hline \multirow[t]{2}{*}{ Artigas } & 151 & 1,172 & Varela & 59 & 2,220 \\
\hline & & & Lavalleja & 39 & 2,385 \\
\hline \multirow[t]{4}{*}{ Frequência $<39$ e OME $<1,9$} & & & \multicolumn{3}{|l|}{ Frequência < 39 e OME > = 1,9 } \\
\hline & & & Rivera & 26 & 2,500 \\
\hline & & & Aparicio Saravia & 18 & 2,167 \\
\hline & & & Ninguno & 18 & 2,000 \\
\hline Forlan & 10 & 1,800 & Oribe & 16 & 2,313 \\
\hline \multirow[t]{4}{*}{ Wilson_Ferreira } & 6 & 1,833 & Batlle & 14 & 2,286 \\
\hline & & & Luis Suarez & 14 & 2,214 \\
\hline & & & Tabare Vazquez & 9 & 2,333 \\
\hline & & & Mujica & 7 & 2,000 \\
\hline
\end{tabular}

Fonte: Sistematização das autoras com base em Aguirre e Ruiz (2017); Cerri, Caimi e Mistura (2017); González Calderón, Cerri e Rosso (2016) e Alvez Cavanna e Quirici (2017).

Recordemos que Abric $(1993 ; 1998 ; 2001)$ aponta, como caraterísticas essenciais do núcleo central das representações sociais, a hierarquia e a estabilidade, e em torno do núcleo central (quadrante superior esquerdo) orbitam as imagens intermediárias e periféricas. As representações que estão em vias de se consolidar como centrais, ou representações outrora centrais que começam a sofrer desgaste, são encontradas em zonas intermediárias das representações (quadrante superior direito e quadrante inferior esquerdo). Por fim, temos as representações periféricas e menos estáveis (quadrante inferior direito), que contestam as visões do núcleo central.

Debruçando-nos inicialmente sobre o primeiro quadrante de cada tabela/país, que diz respeito ao núcleo central das representações sociais dos estudantes, observamos algumas semelhanças e, também, algumas 
singularidades. Argentina, Chile e Uruguai mostram similitudes na composição do núcleo central, na medida em que os estudantes indicam o nome de personagens habituais da narrativa histórica escolar, considerados protagonistas das epopeias nacionais, em especial no que tange às guerras de conquista ou aos pais fundadores da pátria, que figuram como heróis do panteão político oficial.

Assim, no caso da Argentina, temos menção a San Martín, reconhecido como o libertador das Américas, "figura sobre-humana e fator de reconciliação das parcialidades na segunda metade do século XIX" (AGUIRRE; RUIZ, 2017, p. 3); e a Belgrano, militar que liderou as tropas argentinas na guerra pela independência e compôs o primeiro governo da jovem nação.

No caso chileno, figuram no núcleo central o nome de três próceres nacionais que constituem o período fundacional desta nação: Bernardo O'Higgins, "consagrado como um general vitorioso que deu a independência à pátria” (GONZÁLEZ CALDERÓN; CERRI; ROSSO, 2016, p. 14); Arturo Prat, protagonista da guerra do Pacífico e alçado ao papel de figura paterna em busca da identidade em época de crise; e José Miguel Carrera, apresentado na narrativa histórica oficial como um autêntico caudilho da revolução criolla, herói elegante e simpático.

No núcleo central das representações sociais dos estudantes uruguaios temos a presença hegemônica de Artigas, considerado o pai da pátria e representante máximo das efemérides, cuja data de nascimento (19 de junho) remete a um feriado nacional.

No caso brasileiro, temos que o nome mais prontamente lembrado foi o do descobridor Pedro Álvares Cabral (OME 1,528), embora na frequência das evocações figure apenas em quarto lugar. Pode-se interpretar a presença de Cabral como um ícone, não de si mesmo, considerando o pouco que se estuda de sua biografia, mas da ação dos portugueses na conquista do território; conteúdo escolar tornado canônico, mas sem função exemplar, ou seja, não se trata de um sujeito cuja vida inspira as novas gerações. Destaca-se também, em frequência de evocação, o nome de Tiradentes, símbolo construído pelo movimento republicano brasileiro como mártir da independência, em oposição ao marco monarquista representado por 
D. Pedro I, que aparece com relevância bastante menor, embora dentro do núcleo central. Note-se, ainda, a presença destacada de nomes como Getúlio Vargas e Juscelino Kubitschek, e nomes agrupados na categoria religiosos ${ }^{3}$, em sua maioria personagens do século XX. Isto evidencia o peso da história recente na definição do núcleo central da representação social de heróis por parte dos jovens brasileiros.

Este dado pode ser lido como indício de um novo pressuposto da história escolar, a superação da ideia de que a História consiste no estudo do passado remoto, sem interlocuções com o tempo mais recente. Comparando com os resultados anteriormente apresentados nos estudos da Argentina, Chile e Uruguai, pode-se lançar a hipótese de que se trata de um traço específico da cultura histórica brasileira, um país que se caracteriza por dimensões continentais e práticas culturais bastante diversas nas várias regiões, cujo processo de independência foi bastante peculiar em relação aos outros três países. Por outro lado, há relevantes semelhanças na composição do núcleo central das representações entre os quatro estudos, na medida em que todos evidenciam nomes de personagens masculinos, vinculados à história política e militar, com ênfase à história nacional em detrimento das regionalidades.

É preciso reconhecer, portanto, que o patamar de herói nacional concedido a esses personagens não está relacionado apenas (e sobretudo) à narrativa escolar. Em torno deles mobilizou-se um grande esforço para constituir uma consciência histórica de matriz/constituição de sentido tradicional e exemplar, reforçada no cotidiano das pessoas, pelas efemérides, nos nomes de ruas, escolas, museus, na moeda nacional e até em marcas de erva-mate, como anunciam Alvez Cavanna e Quirici (2017). A consciência histórica, em seu sentido tradicional, segundo Cerri (2011, p. 100-101), direciona atenção para a memória das origens, sendo a identidade erigida pela capacidade de "imitar ou emular as definições culturais preexistentes das formas de convivência”. Já a consciência histórica, em seu sentido exemplar, busca determinadas experiências do passado para

\footnotetext{
${ }^{3}$ A categoria religiosos reuniu 165 evocações, de alguma maneira relacionadas à fé, capitaneada pelo médium Chico Xavier, com 60 evocações; seguindo as menções a Deus, com 49 evocações; e a Jesus Cristo, com 29 evocações.
} 
"reforçar as regras gerais de conduta predominantes em uma dada sociedade", possibilitando a articulação entre o passado, o presente e o futuro, pela validação contínua dessas regras.

Reportando-nos ao quadrante superior direito, que representa a primeira zona intermediária ao núcleo central, novamente identificamos similitudes nos dados da Argentina, Chile e Uruguai e algumas particularidades no caso brasileiro. Note-se que, entre estudantes uruguaios e argentinos, a marcação em branco figurou, respectivamente, como a primeira e a segunda evocação mais frequente. Nessa primeira zona intermediária, jovens argentinos, chilenos e uruguaios continuam a evocar nomes de próceres da nação, como o intelectual e político Domingo Sarmiento, na Argentina; Manuel Rodriguez, símbolo da luta independentista no Chile; no Uruguai, José Pedro Varela, fundador da escola pública, e Lavalleja, político e militar do século XIX, envolvido nas lutas pela independência daquele país.

No caso brasileiro, os dados mostrados na primeira zona intermediária mantêm a mesma particularidade evidenciada no núcleo central, uma vez que ali constam nomes predominantemente contemporâneos (dos séculos XX e XXI), à exceção da presença da Princesa Isabel, personagem do século XIX, construída como a libertadora dos escravos. Neste quadrante figura o nome de Lula que, com 610 evocações, só não consta no núcleo central das representações sociais devido à ordem média de evocação (1,957); e o nome de Dilma Rousseff, então presidente do Brasil. As demais evocações deste quadrante foram consubstanciadas em quatro categorias: nomes do esporte, com 389 evocações, que agrega destacados jogadores de futebol, notadamente o ídolo Pelé (190 evocações) e o piloto Airton Senna (81 evocações); ressignificação, com o total de 303 evocações, que traz em destaque menções a familiares (pai, mãe, avós, tios, irmãos etc.), e a personagens coletivos (professores, indígenas, trabalhadores) como heróis da história do país, denotando a recusa de parte dos estudantes em cultuar as chamadas memórias de bronze; irreverência, com 216 evocações, contém nomes de heróis da ficção em quadrinhos, personagens da mídia e outras manifestações que mostram modos criativos e originais de representar os 
heróis nacionais; por fim, a categoria nomes da música, constituída por 145 evocações, representada por músicos como Renato Russo, Cazuza, Luiz Gonzaga e Raul Seixas, dentre outros.

O quadrante inferior esquerdo de cada tabela representa a segunda zona intermediária ao núcleo central, compondo o sistema periférico das representações sociais. Trata-se, segundo Abric (2001, p. 78), de uma "interface entre a realidade concreta e o sistema central", que mostra a mobilidade e o dinamismo das representações sociais. Aqui já se observa maior diversidade de personagens na indicação dos estudantes e, também, mais aproximação entre os quatro países. Note-se que, com exceção da Argentina, em que os jovens apontaram Cristóvão Colombo e ninguém com maior frequência e menor OME; nos dados do Brasil, Chile e Uruguai aparecem tanto nomes de próceres da nação (D. Pedro II, Caxias, Pedro de Valdívia, Colombo) como nomes contemporâneos, que representam ícones do esporte (Forlan), políticos marcantes (Allende, Wilson Ferreira), líderes sociais (Chico Mendes, Zilda Arns), etc.

Contudo, é no quadrante inferior direito; isto é, na periferia do sistema de representações sociais, que se encontra a maior movimentação e diversidade de personagens tidos pelos jovens como heróis nacionais, evidenciando que a periferia é efetivamente o lugar dos paradoxos e contradições, funcionando como uma espécie de para-choque em relação ao núcleo central. Note-se que toda a sorte de personagens compõe o sistema periférico, podendo-se constatar extrema semelhança entre os quatro países, neste quadrante. Destaca-se a coexistência de nomes de próceres do panteão nacional, com personagens da cultura, da música, do futebol, da política. São personagens identificados temporalmente em uma larga duração, que se estende do século XVI ao século XXI, denotando uma ideia de linearidade temporal e continuidade. Esses extremos podem ser ilustrados com os nomes de Cristóvão Colombo, passando por Mitre, Violeta Parra, até chegar a personagens como Mujica e Maria da Penha, por exemplo. 


\section{CONSIDERAÇÕES FINAIS}

Em um esforço de síntese reflexiva, buscamos recuperar algumas linhas de força que permitem uma aproximação à questão central deste estudo, cujo propósito é compreender as interpretações que os estudantes fazem do passado, notadamente no que se refere às suas representações sociais sobre heróis nacionais, considerando as implicações entre a consciência e a cultura histórica, a construção da nacionalidade/identidade nacional e o ensino da História na escola.

Um primeiro aspecto a ser destacado, tomando os dados em seu conjunto, é a similitude manifestada no núcleo central e nas duas primeiras zonas intermediárias das representações sociais dos estudantes argentinos, chilenos e uruguaios, e a singularidade/diferenciação da experiência brasileira. O centro de gravidade da representação social dos estudantes dos três países está localizada na temporalidade mais remota, predominantemente entre os séculos XVI e XIX, e circunscrita aos heróis do panteão político oficial, às chamadas memórias de bronze. A presença tão marcante de tais personagens nas representações sociais destes estudantes indica a formação de uma consciência histórica com funções tradicional e exemplar. A função tradicional, de acordo com Rüsen (2001), enfatiza a origem e a permanência de determinado modelo cultural comum, cuja moralidade se apresenta como um conceito preestabelecido e inquestionável, em que o tempo é eternizado como sentido. Já a função exemplar constitui-se na interação entre as regras gerais e a experiência histórica, em que o tempo é expressado como sentido.

Os heróis nacionais que habitam as representações sociais dos jovens argentinos, chilenos e uruguaios cumprem função tradicional, no sentido de se remeter à memória das origens e função exemplar, na medida em que se busca as experiências do passado para reforçar determinadas condutas a serem adotadas na vida prática: no caso dos próceres, são modelos de coragem, abnegação, amor à pátria e à coletividade, dentre outras virtudes. Os dados fornecidos pela pesquisa realizada com os jovens brasileiros direciona-nos à hipótese de que, em sua consciência histórica, coexistem as funções tradicional e exemplar, agregando a elas indícios das funções crítica 
e genética, uma vez que percebemos, na totalidade dos quadrantes, desde o núcleo central até a periferia, a presença de diversos sujeitos históricos que representam forças de resistência e de negação de ideias e práticas sociais hegemônicas. Estas características que se apresentam em todos os quadrantes, no caso das representações sociais dos jovens brasileiros, é encontrada apenas na última periferia (quadrante inferior direito) entre os jovens que compõem o estudo na Argentina, Chile e Uruguai. Disso depreende-se que o núcleo central das representações sociais, no caso brasileiro, contém menor hierarquia e estabilidade em relação aos outros países integrantes da pesquisa. Ainda, evidencia que uma característica tão extensa e plural da periferia permite-nos visualizar a representação social como um sistema vivo, dinâmico, em constante movimento.

Sem o aprofundamento dos estudos é difícil afirmar as razões dessa particularidade brasileira, mas se pode levantar algumas hipóteses: 1) as dimensões geográficas e a diversidade cultural do Brasil desfavorecem a construção de uma identidade nacional mais homogênea; 2) há menor efetividade dos agentes/instituições públicos brasileiros (Igreja, Escola, Exército, Imprensa, Estado) na preservação dos rituais e monumentos cívicos que impactem a cultura histórica das novas gerações; 3) visualiza-se um movimento de certa resistência/irreverência dos professores e estudantes frente a uma tradição escolar e a um modelo de ensino de História que prioriza o estudo dos chamados grandes homens, das efemérides e das temporalidades remotas.

Uma segunda linha de força, evidenciada nos estudos que analisamos, refere-se à presença de categorias como ressignificação, irreverência e câmbio de significado, as quais expressam atitudes de recusa dos estudantes frente ao sistema tradicional de representação dos personagens que figuram na história nacional e na cultura histórica. Em tais categorias está consubstanciada a presença de anti-heróis, de celebridades e subcelebridades da mídia, de personagens da ficção, figuras de resistência e contra-hegemonia, dentre outros. Ganha destaque, também, a ocorrência de categorias como en blanco, nadie, ninguno, ninguém, revelando que, ao menos no sistema periférico de suas representações sociais, parte dos jovens estão a negar 
que existam heróis, aproximando-se da visão de Gumbrecht (2011), que alerta sobre a perda da convicção de que a História tenha algo a nos ensinar para a condução da vida cotidiana, ainda que se visualize maior interesse pelo passado, notadamente em museus, programas de televisão, livros, filmes, patrimônio histórico etc. Este autor explica a falta de legitimação pedagógica da História argumentando que, "desde muitas décadas, ninguém realmente leva a sério personagens da história como modelo de atuação" (GUMBRECHT, 2011, p. 28).

Outro ponto a ser destacado, em uma análise que considere o conjunto dos países que compõem a pesquisa, concerne à presença hegemônica das figuras masculinas indicativas dos heróis nacionais nas representações sociais dos estudantes. Note-se que no núcleo central das representações figuram apenas homens, predominantemente políticos, militares e conquistadores. Nos quadrantes superior direito e inferior esquerdo estão ausentes as figuras femininas no caso da Argentina, Chile e Uruguai. As mulheres comparecem nos três quadrantes periféricos da amostra brasileira, sendo representadas por apenas quatro nomes: Princesa Isabel, Dilma Rousseff, Zilda Arns e Maria da Penha. Na amostra uruguaia não figuram nomes femininos e, no caso de Argentina e Chile constam, respectivamente, os nomes de Eva Perón e de Violeta Parra. Na mesma direção, estão ausentes das representações sociais dos jovens que integram os estudos nos quatro países, os sujeitos históricos ligados aos povos afrodescendentes e às populações indígenas. A única exceção identificada nessa dimensão étnica é a presença de Zumbi, um dos líderes do Quilombo dos Palmares, que figura no quadrante inferior direito na amostra brasileira. Entendemos que este dado denota o embate entre uma cultura histórica que favorece as representações de gênero masculinas, brancas e europeias como referências reconhecidas de exemplaridade histórica, de conduta e cidadania; e as novidades do conhecimento histórico disciplinar, que já discutiu, incluiu e apropriou-se destes personagens na composição da compreensão e do conhecimento histórico acerca do passado.

A visualização da galeria de heróis eleita pelos estudantes argentinos, brasileiros, chilenos e uruguaios motiva a seguir perguntando sobre 
o papel da escolarização das histórias nacionais para a formação de identidades sociais e históricas, e do ensino de História, quando se coloca à serviço, como instrumento, da manutenção da cultura histórica vigente e do funcionamento das representações sociais. Embora tenhamos lidado com representações que não tiveram necessariamente proveniência, em sua construção, do ambiente escolar, já que as expressões de cultura histórica abrigam diversas fontes de informação, é forçoso admitirmos e importante percebermos o potencial construtivo (e ao mesmo tempo controlador) da história escolar. Isto porque ela é capaz de fornecer alimento à memória dos estudantes, e operar com recortes, lembranças e esquecimentos, próprios de seu domínio.

Neste sentido, a tarefa de aproximação das interpretações dos estudantes sobre o passado histórico é produtiva, porque permite, também, questionarmos sobre que história e a história de quem é ensinada na escola, e assumirmos responsabilidades frente a um conhecimento disciplinar e escolar que possui uma maleabilidade perigosa, no que diz respeito à produção de violências culturais e amarras morais, identitárias e de poder.

\section{REFERÊNCIAS}

ABRIC, J. C. Central system, peripheral system: their functions and roles in the dynamics of social representations. Papers on Social Representations/ Textes sur les représentations sociales. Áustria/Reino Unido, v. 2, n. 2, p. 75-78, 1993.

ABRIC, J. C. A abordagem estrutural das representações sociais. In: MOREIRA, A. S. P; OLIVEIRA, D. C. de. Estudos interdisciplinares de representação social. Goiânia: AB Editora, 1998, p. 27-38.

ABRIC, J. C. Práticas sociales y representaciones. México: Ediciones Coyoacán, 2001.

AGUIRRE, M. C.; RUIZ, M.C. Entre el desconocimiento juvenil y las nuevas demandas de ejemplaridad. Las representaciones sobre los héroes en la Argentina actual, 2017 (mimeo). 
ALVES-MAZZOTTI, A. J. Representações sociais: aspectos teóricos e aplicações à educação. Em Aberto, Brasília, v. 14, n. 61, jan./mar. 1994, p. 60-78.

ALVEZ CAVANNA, F.; QUIRICI, G. Héroes del Uruguay, 2017 (mimeo).

CARRETERO, M. Documentos de identidade: a construção da memória histórica em um mundo globalizado. Porto Alegre: Artmed, 2010.

CARVALHO, J.M.de. A formação das almas: o imaginário da República no Brasil. São Paulo: Companhia das Letras, 1998.

CERRI, L. F.; CAIMI, F. E.; MISTURA, L. A força da cultura histórica: representações de estudantes brasileiros sobre heróis nacionais, 2017 (mimeo).

CERRI, L.F. Ensino da história e consciência histórica. Implicações didáticas de uma discussão contemporânea. Rio de Janeiro: Editora FGV, 2011.

DE CERTEAU, M. A operação histórica. In: LE GOFF, J.; NORA, P. (Dir.). História: novos problemas. 2. ed. Rio de Janeiro: Francisco Alves, 1988.

GUMBRECHT, H.U. Depois de "depois de aprender com a história”, o que fazer com o passado agora? In: NICOLAZZI, F.; MOLLO, H.M.; ARAUJO, V.L. Aprender com a história? O passado e o futuro de uma questão. Rio de Janeiro: Editora FGV, 2011, p. 25-42.

GONZALEZ CALDERÓN, F.; ROSSO, A.; CERRI, L.F. Heróis e cultura histórica entre estudantes no Chile. Revista Brasileira de História. São Paulo, v. 36, nº 71, p. 179-201, 2016.

GRUZINSKI, S. O historiador, o macaco e a centaura: a "história cultural" no novo milênio. Revista Estudos Avançados, São Paulo, v. 17, n. 49, p. 321342, set./dez. 2003.

KUSNICK, M.R.; CERRI, L.F. Ideias de estudantes sobre a história: um estudo de caso a partir das representações sociais. Cultura Histórica \& Patrimônio, Alfenas, v.2, n.2, p. 30-54, 2014.

MICELI, P. O mito do herói nacional. São Paulo: Contexto, 1997. 
MOSCOVICI, S. A representação social da psicanálise. Tradução de Álvaro Cabral. Rio de Janeiro: Zahar, 1978.

PRADO, M.L.C. Repensando a história comparada da América Latina. Revista de História, São Paulo, n. 153, p. 11-33, dez. 2005.

ROMERO, L.A. (Coord.). La Argentina en la escuela. La idea de nación en los textos escolares. Buenos Aires: Siglo XXI Editores, 2004.

RÜSEN, J. ¿Qué es la cultura histórica ?: Reflexiones sobre una nueva manera de abordar la historia. In K. Füssmann, H. T. Grütter, \& J. Rüsen (Eds.), Historische Faszination. Geschichtskultur heute. Weimar, Böhlau, 1994, p. 3-26 (versão traduzida para o espanhol por F. Sánchez Costa e Ib Schumacher).

RÜSEN, J. Como dar sentido ao passado: questões relevantes de metahistória. Revista História da Historiografia, Ouro Preto, n. 2, p. 163-209, mar. 2009.

RÜSEN, J. História Viva. Teoria da história III: formas e funções do conhecimento histórico. Brasília: Editora da UnB, 2007.

RÜSEN, J. Razão Histórica. Teoria da História: os fundamentos da ciência histórica. Brasília: Editora da UnB, 2001.

THIESSE, A.M. Ficções criadoras: as identidades nacionais. Anos 90, Porto Alegre, n. 15, 2001/2002.

VERÍSSIMO, J. A educação nacional. 3. ed. Porto Alegre: Mercado Aberto, 1985.

VIDAL, D.G.; ASCOLANI, A. (Orgs.). Reformas educativas no Brasil e na Argentina: ensaios de história comparada da educação (1820-2000). São Paulo: Cortez, 2009. 